\title{
A pedigree study of perinatally lethal renal disease
}

\author{
A BANKIER, M DE CAMPO, R NEWELL, J G ROGERS, AND D M DANKS
}

From the Departments of Genetics and Radiology, Royal Children's Hospital, Melbourne, Australia.

SUMmARY A family study of perinatally lethal renal disease (PLRD) was undertaken in the State of Victoria, Australia, for the years 1961 to 1980 . A total of 221 cases was ascertained through hospital and necropsy records and confirmed by necropsy findings. There were 134 cases of bilateral renal agenesis (BRA), 34 cases of unilateral agenesis with dysplasia of the other kidney (URA/RD), 42 cases of bilateral renal dysplasia (BRD), and 11 cases of renal aplasia. Parents of 131 babies were interviewed and 153 parents from 82 families had a renal ultrasound examination.

In the period of best ascertainment (1975 to 1980) the frequency of PLRD was $0 \cdot 27$ per 1000 and of BRA $0 \cdot 16$ per 1000 . There were 10 cases of sirenomelia, a frequency of 0.008 per 1000 .

For all families of PLRD, 15 of $423(3.6 \%)$ sibs and three of $1579(0 \cdot 2 \%)$ first cousins were affected. One family had three sibs with BRA and four had two sibs with BRA. One pair of sibs and two first cousins had BRA in one and URA/RD in the other affected. One baby had BRD with an affected first cousin. The nature of the renal lesion was not established.

When the index case had BRA, 14 in $283(5.6 \%)$ sibs had PLRD. Where the index case had BRA and urogenital defects, but no birth defects in other organs, 12 of 148 sibs $(8 \%)$ were affected. None of the sibs had BRA when the index case had BRA as part of a multiple malformation complex.

In the multiple malformation group, however, five of $40(12.5 \%)$ sibs had similar patterns of malformations. Renal ultrasound abnormalities were no more frequent in parents of two affected babies (one of 18) than in the other parents (nine of 135).

Our findings confirm that BRA and URA are genetically related. There are a number of conclusions which are important for genetic counselling. There is a high likelihood of recurrence $(8 \%)$ in sibs when the index case has BRA and urogenital abnormalities alone. When BRA is part of a multiple malformation complex, the risk of recurrence of multiple malformations is significant $(12.5 \%)$, but the risk of recurrence of BRA is low. The finding of renal ultrasound abnormalities in the parents was not informative.

Occurrence of bilateral renal agenesis (BRA) in sibs was first reported by Maddison in $1934 .{ }^{1}$ Over the next 45 years there were only 13 reports of 32 familial instances of BRA or of combined unilateral renal agenesis (URA) with renal dysplasia (RD). ${ }^{2-15}$ The recurrence risk was considered to be low. In 1979 Carter et at published the first systematic family study of BRA and found $3.5 \%$ of sibs to be affected. They found a frequency of BRA of $0 \cdot 12$ per 1000 with a male preponderance (male:female $=2 \cdot 7: 1$ ) and affirmed a genetic link between BRA and URA.

This study was undertaken to establish the fre-

Received for publication 9 May 1984. Accepted for publication 11 July 1984 quency of these conditions, the risk of recurrence in families in the State of Victoria, Australia, and the relationship of BRA, URA, and RD. By detailed examination of the necropsy findings in index cases and by renal ultrasound examination of the parents, we searched for anatomical patterns which may allow the identification of specific subgroups. We wish to confine this report to the anatomical and family findings and their possible significance. Other epidemiological findings will be the subject of a later report.

\section{Methods}

The Consultative Council of Maternal and Perinatal Mortality established a compulsory register of 
neonatal deaths in Victoria from 1962 and a stillbirths register from 1968 . By the late 1970 s, $98 \%$ of perinatal deaths were reported to the Council and the necropsy rate reached $80 \%$. The most complete information was available for 1975 to 1980 . The register included all births of babies over $500 \mathrm{~g}$ in weight or 22 weeks' gestation. Numbers of deaths caused by renal malformations were available. Rules governing confidentiality prevented direct use of the register for case ascertainment, but responsible officers were able to check cases we ascertained against the register and to encourage reporting doctors to contact us.

For the years 1961 to 1980 , cases were ascertained by personal search of hospital and pathology records in the seven metropolitan paediatric and obstetric hospitals and two large country centres. Further cases were ascertained through regional pathologists and directly from doctors who had reported cases to the Consultative Council.

All case reports coded as Potter syndrome, renal agenesis, and polycystic kidneys were examined as well as many cases coded as multiple malformations. Despite this we will have missed some cases coded under an associated defect, for example, spina bifida, or as multiple malformations.

This approach identified all the cases which had been reported to the Council, plus two additional cases never reported to the Council and a number of others which had been coded under one of the other malformations present. Seven cases were subsequently excluded because there had been no necropsy.

All cases accepted into the study had been confirmed by necropsy with the exception of one case of sirenomelia. We included all cases of bilateral renal agenesis (BRA), unilateral renal agenesis with contralateral renal dysplasia (URA/ $\mathrm{RD}$ ), and cases of bilateral renal dysplasia (BRD) which had been lethal in the perinatal period. Renal dysplasia was defined on histology. ${ }^{16}$ Experienced paediatric pathologists assisted in the interpretation of doubtful necropsy reports $(10 \%)$ by reviewing the histological slides. Syndromes with an established cause, such as chromosomal trisomy or specific disorders such as Zellweger syndrome, were excluded.

We excluded from the final study 25 babies with urinary outflow obstruction and gross hydronephrosis, 12 cases of other urethral obstruction with a large bladder without dilated ureters, 14 cases of Triad syndrome, and four cases of bilateral renal hypoplasia. Some family data had been collected before this decision was made and there was no familial occurrence; the number of families studied were $0 / 25,10 / 12,9 / 14$, and $0 / 4$ respectively.
We included 221 cases in this study. There were 134 cases of BRA and 11 cases of aplasia with some renal tissue but no glomeruli. Thirty-four cases had agenesis of one kidney with dysplasia on the contralateral side (URA/RD) and 42 cases had bilateral renal dysplasia (BRD). We will refer to this group as perinatally lethal renal disease (PLRD).

All anatomical details were documented. Twothirds of the necropsies were done by paediatric pathologists and detailed documentation was available in half of the reports.

\section{METHOD OF FAMILY STUDY}

Permission was obtained from the hospital or the doctor who looked after the family. Each family was then contacted by letter seeking their cooperation in the study. A total of 131 families agreed to a personal interview, 52 in their home and 79 at a medical centre. Pedigree information was obtained in a further 17 cases by telephone, letter, or from records. Twelve doctors and 11 families declined permission for the study.

There was insufficient information to identify 15 families and we were unable to trace 34 families because of repeated changes of address. Of these, six were known to have left the state. One of us (AB) interviewed 125 of the families.

Family and pregnancy history were documented. Family history included first, second, and third degree relatives. Confirmation of renal disease or perinatal deaths in the family was sought by contacting the doctor or the hospital. Many of the perinatal records were inadequate for confirming the cause of death in relatives.

A total of 153 parents from 82 families had renal ultrasound examinations. Nine sibs were also examined; six were sibs in families with more than one member affected, and one was the surviving twin of an affected member.

\section{Results}

\section{BIRTH FREQUENCY}

There were 1.25 million births in Victoria in the period of 1961 to 1980 . The frequency of BRA was $0 \cdot 11$ per 1000 , and for all PLRD $0 \cdot 18$ per 1000 . There were 10 cases of sirenomelia, a frequency of 0.008 per 1000 . In the period of best ascertainment (1975 to 1980) the frequency of BRA was $0 \cdot 16$ per 1000 and for PLRD 0.27 per 1000.

TWINS

There were nine twin index patients, of whom three had sirenomelia. All were discordant for PLRD. Six of the index twins were male and three female. Two pairs of twins were considered to be identical on the 
basis of recorded monochorionic monoamniotic placentas. Seven co-twins were normal. One twin died of neonatal hepatitis at 6 weeks; one twin whose index twin had BRA and spina bifida died with spina bifida.

\section{SIBS}

To correct for ascertainment bias, each separately ascertained affected subject was treated as an index case. Fifteen of the 423 sibs were also affected, a frequency of $3.6 \%$. We had ascertained all but two as index cases. One had not been reported to the Council and the second was recorded as 'Potter syndrome', but had not been accepted as an index case because the necropsy report could not be located. One family, who had lost a son and daughter with BRA, had BRA diagnosed by ultrasound in a subsequent pregnancy during the study. BRA was confirmed in the female fetus after termination at 17 weeks. The number of affected sibs of BRA index cases only was 14 of $238(5.9 \%)$. The remaining categories of PLRD contributed only one of $185(0.005 \%)$ affected sibs. Information about other defects in sibs and in index cases will be discussed later.

\section{UNCLES AND AUNTS}

Nine of 991 aunts and uncles had urogenital anomalies, one had spina bifida, and five had congenital heart disease.

\section{cousins}

There were 1579 first cousins. Three had PLRD (one BRA, one RA with R Dys, one with BR Dys), a frequency of $0 \cdot 2 \%$. Seven had other urogenital abnormalities including hydronephrosis diagnosed by ultrasound (in the course of the study) in a sister of the proband with BRA; the cousin also had BRA. Seven had congenital heart disease. One had anal atresia and a dysplastic hydronephrotic kidney and survived with surgery. Three had neural tube defects.

TABLE 1 Necropsy findings in PLRD.

\begin{tabular}{ll}
\hline Urinary tract and adjacent structures involved (150 patients) \\
95 & Urinary tract alone \\
14 & Anorectal atresia \\
39 & Anomalies of internal genital tract \\
36 & Anomalies of extcrnal genitalia \\
12 & Sirenomelia/sacral and vertebral anomalies \\
Multiple malformations (7l patients) \\
13 & Neural tube defect \\
24 & Microcephaly. eyc defect \\
9 & Cleft lip/palate \\
10 & Tracheo-oesophageal fistula \\
27 & Congenital heart disease \\
2 & Diaphragmatic hernia \\
19 & Atresia of small or large intestinc \\
\hline
\end{tabular}

Note: in some cases more than one abnormality was present.
CONGENITAL MALFORMATIONS IN INDEX CASES

The necropsy reports were examined with attention to associated malformations which may constitute distinct subgroups (table 1).

In $68 \%$ of PLRD cases the defects were confined to the urogenital system with or without anal atresia, but $32 \%$ of cases had multiple malformations; $5.9 \%$ had neural tube defects and $12 \%$ cardiac abnormalities. Microcephaly was recorded in $10 \%$ of all necropsy reports (head circumference at least $1 \mathrm{~cm}$ below the 10th centile for gestational age).

\section{IN DEX CASES WITH BRA}

Since the BRA group was the largest of the four groups of PLRD, and since most familial occurrence was observed in this group, the associated malformations were examined in detail (table 2).

Group $A$ comprised 80 cases with defects in anatomically adjacent structures only. In 53 of the 80 cases $(66 \%)$ the urinary tract alone was affected. Ureteric remnants were documented in two of these cases. The bladder was normal in six, absent in 11, and hypoplastic in 36 . Internal genital abnormalities were present in 11 of the 21 females and absent seminal vesicles in one male. In most males there was no comment on the state of the internal genitalia (other than testes). External genital anomalies were present in one female and seven males. Anal/rectal atresia was present in four cases. In the remaining three cases there was no comment on the state of the urogenital tract other than BRA.

Group $B$ (17 cases) included BRA with minor skeletal abnormalities, microcephaly, or cataracts (see appendix 1$)$. In nine cases $(53 \%)$, the urinary tract alone was affected. All had a hypoplastic bladder and ureteric remnants were present in one. Two of the five females had atresia of the internal genitalia and four males had abnormalities of the external genitalia. There was bladder agenesis in four cases and anal/rectal atresia in four cases.

Group $C$ were nine cases of sirenomelia with BRA. All had ureteric atresia and bladder anomalies, as well as variable agenesis of internal and external genitalia, anorectal atresia, and lower limb defects. Atresia of the bladder was seen in six and hypoplasia in two cases.

In the other cases of BRA, groups $D$ to $F$, there were defects in other organs. Twenty-seven of the 28 cases had anal and genital anomalies as well as the urinary tract defects. Ureteric remnants were found in one case, bladder agenesis in five, hypoplasia in 18 , and a normal bladder in one case. Agenesis of the internal genitalia was present in 13 of the 17 females and absence of seminal vesicles was noted in one male. There were four cases of BRA with

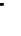


TABLE 2 Urogenital and anal necropsy findings in the subgroups, classified according to the associated birth defects.

\begin{tabular}{|c|c|c|c|c|c|c|c|c|}
\hline & $\begin{array}{l}B R A \\
(n=134)\end{array}$ & $\begin{array}{l}\text { Defect of } \\
\text { urinary tract } \\
\text { alone }\end{array}$ & $\begin{array}{l}\text { Ureteric } \\
\text { atresia }\end{array}$ & $\begin{array}{l}\text { Bladder: } \\
\text { normal, } \\
\text { hypoplastic. } \\
\text { agenesis }\end{array}$ & $\begin{array}{l}\text { Atresia of } \\
\text { internal } \\
\text { genitalia } \\
(F)\end{array}$ & $\begin{array}{l}\text { Atre } \\
\text { exte } \\
\text { geni } \\
(F)\end{array}$ & $\begin{array}{l}\text { ia of } \\
\text { ial } \\
\text { (M) }\end{array}$ & $\begin{array}{l}\text { Anal } \\
\text { atresia }\end{array}$ \\
\hline \multirow[t]{3}{*}{ A } & BRA + urogenital & & & 9 & & & & \\
\hline & $(n=80)$ & 53 & 78 & 51 & 11 & 1 & 7 & 5 \\
\hline & F 21, M 59 & $(66 \%)$ & $(97.5 \%)$ & 12 & & & & $(6 \cdot 8 \%)$ \\
\hline \multirow[t]{3}{*}{ B } & $\begin{array}{l}A \pm \text { microcephaly } \\
\pm \text { eye }\end{array}$ & & & - & & & & \\
\hline & \pm skeletal & 9 & 13 & 11 & 7 & & 4 & 9 \\
\hline & $\begin{array}{l}(n=17) \\
\text { F } 5, M 12\end{array}$ & $(50 \%)$ & & 7 & & & & \\
\hline \multirow[t]{3}{*}{ C } & Sirenomelia & & & - & & & & \\
\hline & $(n=9)$ & - & 9 & 1 & 3 & & 9 & 9 \\
\hline & F $3, M^{2}$ & & & 6 & & & & \\
\hline \multirow[t]{3}{*}{ D } & $A+T O F$ & & & - & & & & \\
\hline & $(n=4)$ & - & 4 & 4 & 2 & 1 & - & 3 \\
\hline & F $2, M 2$ & & & - & & & & \\
\hline \multirow[t]{3}{*}{ E } & $A+N T D$ & & & 1 & & & $\cdot$ & \\
\hline & $(n=6)$ & 1 & 6 & 3 & 4 & - & - & 1 \\
\hline & F $5 . M 1$ & & & - & & & & \\
\hline \multirow[t]{3}{*}{$\mathrm{F}$} & $A+C V+$ other & & & - & & & & \\
\hline & $(n=18)$ & 5 & 17 & 11 & 7 & 3 & 7 & 9 \\
\hline & F 10, M 8 & $(28 \%)$ & & 5 & & & & $(56 \%)$ \\
\hline
\end{tabular}

In the remainder of cases the status of the organ was not specified in the necropsy report.

tracheo-oesosphageal fistula (three of these had anal atresia as well), six with neural tube defects, and 18 cases with multiple malformations.

In the multiple malformation group F (18 cases) there were, in addition to urogenital abnormalities, defect of the heart (18), microcephaly (4), neural tube defect (5), brain malformation (2), tracheooesophageal fistula (2), cleft lip/palate (4), and skeletal abnormalities (3) (appendix 2). In 15 cases, three or more organ systems were affected. Looking at the urogenital system in this group, abnormalities of the urinary tract alone were seen in five, ureteric remnants were present in one, four had agenesis and 11 hypoplasia of the bladder.

In summary, urogenital and anal abnormalities were more often seen in association with BRA when BRA was part of a multiple malformation complex. Isolated BRA and urinary tract defects, without genital or anal defects, were seen in cases which did not have malformations in other organs. Bladder agenesis was seen in $17 \%$ of cases (excluding sirenomelia). Of all cases of BRA, four had ureteric remnants, a frequency of $3 \%$. There was no recurrence of BRA in groups $D$ to $F$ where the index cases had birth defects in other organs as well as BRA.
PLRD IN SIBS OF INDEX CASES WITH BRA

Malformations in sibs were documented at the time of interview and confirmed by examination of medical records. Table 3 shows that familial occurrence of PLRD was confined to groups A and B, that is, to those with urogenital defects alone or with urogenital defects plus microcephaly/eye/minor skeletal defects, suggesting that these two groups are aetiologically similar and separate from groups $\mathrm{D}$ to $\mathrm{F}$ in which other organ systems were affected. In each instance the affected sib also had urogenital abnormalities without defects in other organs.

The pair of sibs with BRA in group B had a very similar array of anomalies which may constitute a distinct autosomal recessive syndrome. Both had BRA, bladder agenesis, eye anomalies, and digital anomalies, and one had choanal plus laryngeal atresia. The affected first cousin of a different case in group B had microcephaly and a cataract.

\section{BIRTH DEFECTS OTHER THAN PLRD IN SIBS OF} B R A

There was a higher than expected frequency of cardiac, urogenital, and neural tube defects in sibs of group $\mathrm{F}$.

In group $A$ there were just one sib with 
TABLE 3 Birth defects in sibs of BRA.

\begin{tabular}{|c|c|c|c|c|c|c|c|c|}
\hline \multicolumn{3}{|l|}{ Index case } & \multicolumn{6}{|l|}{ Sibs } \\
\hline$B R A$ & No & $\%$ PLRD & $B R A$ & $R A / R D$ & $B R D$ & $C V S$ & $C N S$ & Urogenital \\
\hline $\begin{array}{l}\text { A } \\
(80)\end{array}$ & 148 & 8 & $10(+1)$ & 1 & - & 1 & 1 & 1 \\
\hline $\begin{array}{l}\text { B } \\
\text { (17) }\end{array}$ & 25 & 8 & 2 & $\begin{array}{l}\text { 1st } \\
\text { cousin }\end{array}$ & - & - & - & 1 \\
\hline $\begin{array}{l}\mathrm{C} \\
\text { (9) }\end{array}$ & 9 & 0 & - & - & - & - & 1 & 1 \\
\hline $\begin{array}{l}\text { D } \\
\text { (4) }\end{array}$ & 9 & 0 & - & - & - & $\begin{array}{l}\text { lst } \\
\text { cousin }\end{array}$ & $\begin{array}{l}\text { 1st } \\
\text { cousin }\end{array}$ & \\
\hline $\begin{array}{l}\mathrm{E} \\
(6)\end{array}$ & 7 & 0 & - & - & - & & 1 & \\
\hline $\begin{array}{l}F \\
(18)\end{array}$ & 40 & 0 & - & - & - & 5 & 1 & 3 \\
\hline $\begin{array}{l}\text { Total } 134 \\
\text { (18) }\end{array}$ & 238 & 5.9 & & & & & & \\
\hline
\end{tabular}

vesicoureteric reflux and another with spina bifida. In group B one sib had hydronephrosis. In group C three of the nine cases were one of twins, discordant for sirenomelia. In one twin pair the index case had sirenomelia with BRA, hydrocephalus, and multiple vertebral anomalies, and the other twin had spina bifida.

There was an unexpectedly high frequency of malformations in the sibs of index cases in group $F$ (appendix 2). Information was available on 12 of these 18 families. Five sibs had congenital heart disease (two truncus arteriosus, two tetralogy of Fallot, one pulmonary valve stenosis) and three of these sibs died in the perinatal period. One sib had unilateral renal agenesis. The other two shared patterns of malformations with the index case. One of these index cases had BRA, atrial and ventricular septal defects with cebocephaly, and absent olfactory nerves. The sib died with hypoplastic kidneys and hydroureters, tetralogy of Fallot, and absent corpus callosum. In the second pair the index case had BRA with atrial and ventricular septal defects, and the sib died of hydronephrotic dysplastic kidneys, bicornuate uterus, and truncus arteriosus.

In summary, five of the 40 sibs $(12.5 \%)$ had birth defects. In addition, an uncle died of spina bifida and congenital heart disease, and an aunt died of congenital heart disease in the neonatal period. We believe that the high frequency of birth defects in the sibs of the multiple malformations subgroup of BRA may indicate autosomal recessive syndromes.

\section{INDEX CASE WITH URA/RD}

Twenty cases were classified as group A, seven as group B, one had sirenomelia, and six had defects in other organ systems. The pattern of urogenital findings was similar to the BRA group, in that the defects of the urinary tract alone were more often seen in cases where there were no defects in other organ systems (group A 14/20, group B 4/7, groups $D$ to $F 1 / 5$ ). Note that for both BRA and URA/RD the pattern of findings in subgroups $A$ and $B$ are the same.

No ureteric remnants were found on the side of the absent kidney. The ureter of the dysplastic kidney was abnormal (atresia/ectopia/duplex) in 14 cases and normal in 13 cases. The bladder was absent in two, normal in four, and hypoplastic in the remainder of cases.

One sib and one first cousin had BRA where the index cases had URA/RD, with no birth defects in other organ systems.

INDEX CASE WITH BRD

Of the 41 cases, 31 were group A, five group B, and five had other organ defects (two anencephaly, three congenital heart disease). Genital and anal atresia were present in only six cases. The kidneys were hypoplastic ( $10 \mathrm{~g}$ or less and less than half that expected for body weight) in 26 cases and normal in weight in 15 . Renal dysplasia was the only abnormality (ureters and bladder normal) in 15 cases. Ureters were normal, but the bladder was hypoplastic in six and hypoplasia/atresia of the ureters with hypoplastic bladder were found in 20 , with bladder agenesis in one case. There was no difference in the pattern of findings between cases with renal tract defects alone and those with anencephaly or cardiac defects.

One first cousin had been called 'Potter syndrome' but the specific nature of the renal lesion was not known. One sib had anencephaly where the index case had anencephaly as well as BRD.

INDEX CASE WITH RENAL APLASIA

There were 11 cases. Nine were bilateral and two had unilateral nubbins of renal tissue $(<3.5 \mathrm{~g})$ with no glomeruli and only rudimentary tubular 
structures. Ureters, when present, were abnormal. Two cases had microcephaly and cataracts, one with an atrial septal defect and another with tracheooesophageal fistula. There were no affected sibs. This group is best considered with the BRD group.

\section{ULTRASOUND INVESTIGATION OF FAMILY \\ MEMBERS}

Of the 296 parents, 153 had a renal ultrasound examination and 10 abnormalities were detected, a frequency of $6 \cdot 5 \%$ (appendix 3 ). Renal abnormalities were no more frequent in parents with two affected children than in other families (one of 18 or $5.6 \%$, compared to nine of 135 or $6 \cdot 7 \%$ ).

\section{Discussion}

The only other systematic study of renal agenesis was published by Carter et al in $1979 .^{6}$ The frequency of BRA was 0.12 per 1000 compared to our findings of $0 \cdot 16$ per 1000 . Because of good perinatal records in Victoria, our ascertainment is likely to have been more complete, but still an underestimate of the true frequency. We expect to have missed a number of cases recorded under the associated birth defects. We included BRA cases and perinatally lethal cases of URA/RD, BRD, and renal aplasia. The overall frequency of PLRD was $0 \cdot 27$ per 1000 .

We found that $3.6 \%$ (15 in 423 ) of sibs had PLRD. Most of these were from families with BRA cases. Where the index case had BRA, $5.9 \%$ of sibs were affected. In one family there were three affected sibs. In seven of the nine families the two affected babies were independently ascertained, each being recorded as an index case. Carter et al ${ }^{6}$ found, in their cases of BRA, that $3.5 \%$ of sibs (seven in 199) were affected. Both affected sibs were independently ascertained in only one of the six families. Had all the eligible cases born in the period of the study been ascertained (10 cases), the frequency in sibs would have been $5.0 \%$, which is closer to our findings.

BRA and URA/RD occurred in the same families, suggesting that these conditions may be genetically related. The pattern of morphological findings in the two groups was also found to be the same. The relationship of BRA to URA alone may be questioned. The concurrence of BRA and URA in the study of Carter et at had an associated cystic kidney on the contralateral side and there were no occurrences in the 31 sibs of their 18 index cases of URA.

The relationship of BRD to renal agenesis remains unclear. Only one of the familial cases had bilateral renal dysplasia. He had a first cousin documented as having 'Potter syndrome' but the nature of the renal lesion could not be clarified. It is likely that the recurrence risk for renal dysplasia is much lower than for renal agenesis. There were no recurrences of renal aplasia ( 0 of 27 sibs). We believe that these cases are best considered as BRD. It has been suggested that BRA with ureteric remnants is likely to be inherited in a different fashion (possibly autosomal dominant) than those with no remnants. ${ }^{4}$ In this study this lesion was so uncommon that we have no evidence on this point. None of our familial cases with BRA had ureteric remnants.

In the study of birth defects the recognition of meaningful sub-groups of abnormalities has often helped in the search for causes. For example, the association of encephalocele and cystic kidneys led to the definition of Meckel syndrome, an autosomal recessively inherited disorder. ${ }^{17}$ Family studies are particularly useful in delineating aetiologically meaningful groups. By studying affected members of a family one can define the range of expression of the gene. Careful attention to pathological detail may reveal specific histological patterns which can be used to define the syndrome as, for example, the specific histological changes of the liver and kidneys in Meckel syndrome. ${ }^{18}$

These principles were applied to the present study. Examination of malformations associated with BRA revealed apparently distinct subgroups. The pattern of malformations in affected members of the one family were the same and the majority of familial cases had only agenesis of the kidneys and ureters with absent or hypoplastic bladder (subgroup A). Frequency of PLRD in sibs of this group was $8 \%$. The same $8 \%$ frequency in sibs was seen when the urogenital abnormalities were associated with microcephaly, eye, or minor skeletal abnormalities (subgroup B). These figures suggest that these two groups are aetiologically related. Mild microcephaly was present in $10 \%$ of all cases. It is possible that microcephaly, cataracts, and the minor skeletal defects are simply secondary effects of oligohydramnios and at least some of the cases of microcephaly may be between the 3rd and 10th centile and thus be within the normal range of head circumference.

There were no sibs with PLRD in families with index cases who had malformations in other organs as well as in the urogenital system. When the malformations involved two or more organ systems there was a high frequency of urogenital, cardiac, and central nervous system abnormalities in the sibs. It was usual to find the same pattern of abnormalities in both affected sibs. This suggests that there may be several unrecognised autosomal recessive 
syndromes among these cases. While the organ systems involved in some of these families match the Meckel syndrome spectrum, ${ }^{7}$ we feel it is better to reserve this term for those recessively inherited cases with the very specific renal and hepatic microscopic features defined in this condition. ${ }^{18}$

The same trends applied when the index case had URA/RD or BRD, that is, when there was a second case of PLRD in the family, the birth defects were essentially confined to the urogenital system.

On reviewing 14 reports (34 cases) of familial occurrences of PLRD, ${ }^{1-15} 26$ cases had urogenital abnormalities alone. In eight, some other abnormality was recorded (tracheal stenosis, VSD and absent eye; polysplenia; haemangioma of the liver; cardiac dilation; ASD; 'incomplete separation of the hemispheres'; thoracic scoliosis). In only one of these were more than two organs affected (VSD with absent eye). These findings support the findings of the present study.

The higher likelihood of affected sibs in BRA with urogenital anomalies alone (relative to families with BRA plus other defects) suggests that a small insult may be sufficient to cause renal agenesis in a genetically susceptible fetus, whereas a less susceptible fetus requires greater insult which may cause defects in other developing tissues as well as the urinary tract.

Some authors have proposed that renal malformations may arise as an outcome of a gene with autosomal dominant effect with variable penetrance. ${ }^{4}$ Although the frequency of urogenital abnormalities in the general population is not well established, the number of abnormalities found in parents by ultrasound seems close to the frequency generally accepted for the various anomalies identified. Renal abnormalities were no more frequent among the parents with more than one child affected than among those with only one affected. Dominant inheritance seems unlikely in our families.

The frequency of sirenomelia was 0.008 per 1000 . Twinning was frequent (three of 10). One pair of twins was identical and discordant. Sirenomelia babies are known to be born as one of monozygotic twins 100 times as often as singletons. ${ }^{19}$ None of the mothers were known to be diabetic. ${ }^{20}$

For PLRD the frequency of twinning was $4 \%$ and all were discordant as previously reported, although cases in concordant twins have also been reported. ${ }^{15} 21$

In view of the occurrence of PLRD in sibs found in this study, an ultrasound examination in the next pregnancy should be offered to all women who have had a child with PLRD, to look for the presence of kidneys and filling of the fetal bladder. ${ }^{22}$ When the first child had multiple malformations associated with PLRD, a more detailed ultrasound examination is indicated looking, in addition, for cardiac, neural tube, and renal abnormalities.

We would like to acknowledge the valuable assistance of the following pathologists in the interpretation of necropsy findings: C W Chow, D Fortune, and E Gouli. We are grateful to the late Sir Lance Townsend for the information provided from the records of the Consultative Council on Maternal and Perinatal Mortality and to the many doctors who gave permission to examine the records and contact their patients. The following hospitals provided permission for the study: Royal Children's Hospital, Royal Women's Hospital, Queen Victoria Medical Centre, Mercy Maternity Hospital (records only), Preston and Northcote Community Hospital, Western General Hospital, Box Hill Hospital, and Geelong Hospital.

\section{References}

1 Maddison H. Vher das Fehlen beider Nieren. Zentralbl Allg Pathol 1934;60:1-8.

2 Arends NW. Bilateral renal agenesis in siblings. $J$ Am Osteopath Assoc 1957:56:681-4.

3 Baron C. Convington K. Bilateral agenesis of the kidneys in two consecutive infants. Am J Obstet Gynecol 1954:67:667-70.

+ Buchta RM, Viseskul C. Gilbert EF, Sarto GE. Opitz JM. Familial bilateral renal agenesis and hereditary renal dysplasia. Z Kinderheilkd 1973;115:111-29.

5 Cain DR, Griggs D. Lackey DA, et al. Familial renal agenesis and total dysplasia. Am J Dis Child 1974:128:377-80.

- Carter CO, Evans K. Pescia G. A family study of renal agenesis. J Med Genet 1979:16:176-88.

${ }^{7}$ Hack M, Jaffe J, Blankstcin J, et al. Familial aggregation in bilateral renal agenesis. Clin Genet 1974:5:173-7.

$\times$ Kohon G, Borns PF. The association of bilateral and unilateral renal aplasia in the same family. $J$ Pediatr 1973;83:95-7.

${ }^{9}$ Levin H. Bilateral renal agenesis. J Urol 1952:67:860-91.

11) Pashayan HM. Dowd T. Nigro AV. Bilateral absence of the kidneys and ureters. Three cases reported in one family. $J$ Med Genet 1977;14:205-9.

1 Rizza JM. Downing SE. Bilateral renal agenesis in two female siblings. Am J Dis Child 1971;121:60-3.

12 Schinzel A. Homberger C. Sigrist T. Bilateral renal agenesis in 2 male sibs born to consanguincous parents. J Med Genet 1978:15:314-5.

13 Schmidt ECH, Hartley AA, Bower B. Renal aplasia in sisters. Arch Pathol 1952;54:403-7.

14 Whitehouse W, Mountrose U. Renal agenesis in nontwin siblings. Am J Obstet Gynecol 1973:116:88()-2.

15 Yates JRW. Mortimer G. Connor JM, Duke JE. Concordant monozygotic twins with bilateral renal agenesis. $J$ Med Genet 1984:21:66-7.

is Bernstein J. The morphogenesis of renal parenchymal maldevelopment (renal dysplasia). Pediatr Clin North Am 1971:18:395-407.

17 Fraser FC, Lytwyn A. Spectrum of anomalies in the Meckel syndrome. Am J Med Genet 1981:9:67-73.

is Adams CM. Danks DM. Campbell PE. Comments upon the classification of infantile polycystic diseases of the liver and kidney based upon threc-dimensional reconstruction of the liver. J Med Genet 1974;11:234-43.

19 Wright JCY, Christopher CR. Sirenomelia, Potter's syndrome and their relationship to monozygotic twinning. $J$ Reprod Med 1982;27:291-3. 
20) Kallen B, Winberg J. Caudal mesoderm pattern of anomalies: from renal agenesis to sirenomelia. Teratology 1973;9:99-112.

21 Mauer SM, Dobrin RS, Vernier RL. Unilateral and bilateral renal agenesis in monamniotic twins. J Pediatr 1974;84:236-8.

22 Silverman PM, Carroll BA, Moskowitz PS. Adrenal sonography in renal agenesis and dysplasia. $A J R$ 1980;134:600-2.

Correspondence and requests for reprints to Dr A Bankier, Department of Genetics, Royal Children's Hospital, Flemington Road, Parkville, Victoria 3052, Australia.

APPENDIX 1 BRA subgroup $B(n=17)$.

\begin{tabular}{ll}
\hline & Microcephaly \\
1 & Microcephaly with 'buphthalmos' \\
3 & Microcephaly and cataracts \\
1 & Cleft lip and palate \\
1 & Agenesis of lower sacrum and coccyx \\
1 & 'Abnormal' L5 and sacrum, absent toes \\
1 & Absent left ulna and rudimentary hand, absent 2 left toes \\
Sibs & 1 \\
& 'Microphthalmia', laryngeal atresia, syndactyly \\
& Absent left eyelid, syndactyly
\end{tabular}

APPENDIX 2 BRA subgroup $F(n=18)$.

\begin{tabular}{ccl}
\hline 003 & $\begin{array}{c}\text { TAPVD, single ventricle, } \\
\text { coarctation of aorta, } \\
\text { spina bifida, T12-L4 } \\
\text { radiiscisis }\end{array}$ & Normal \\
017 & $\begin{array}{l}\text { VSD, duodenal atresia } \\
\text { Dextrocardia, cleft lip and } \\
\text { palate, fused ribs, absent } \\
\text { radii and thumbs, TOF }\end{array}$ & $\begin{array}{l}\text { Mother } 6 \text { spontaneous abortions } \\
\text { Noterviewed }\end{array}$ \\
045 & $\begin{array}{c}\text { ASD, VSD, hypoplastic } \\
\text { aorta, microcephaly }\end{array}$ & $\begin{array}{l}\text { Sib, cleft lip and palate, } \\
5 \text { spontaneous abortions }\end{array}$ \\
058 & $\begin{array}{c}\text { Coarctation of aorta, PDA, } \\
\text { microcephaly, absent left } \\
\text { radius and fibula, digital } \\
\text { anomalies }\end{array}$ & \\
& $\begin{array}{c}\text { VSD, meningocele. } \\
\text { anorectal atresia }\end{array}$ & Not interviewed \\
071 &
\end{tabular}

.

APPENDIX 3 Ultrasound abnormalities seen in the parents

\begin{tabular}{ll}
\hline Parents & $(n=153)$ \\
2 & No left kidney visualised \\
3 & Left duplex system \\
2 & Vesicoureteric reflux/hydronephrosis \\
1 & Left renal cyst in upper pole \\
1 & Had nephrectomy for renal dysplasia \\
1 & Bicornuate uterus \\
Sister & \\
Vesicoureteric reflux
\end{tabular}

